\title{
Successful closure of anastomotic dehiscence after colon-rectal cancer resection using the Apollo overstitch suturing system
}

Anastomotic dehiscence is the most common cause of postoperative morbidity and mortality. The Overstitch endoscopic suturing system (Apollo Endosurgery, Austin, Texas, USA) is a disposable, single-use suturing device that is mounted onto a double-channel therapeutic endoscope and allows placement of either running or interrupted full-thickness sutures. Several reports have described endoscopic suturing as a treatment option for management of gastrointestinal defects and for stent anchorage [1-5]. To our knowledge, there is no report on the closure of colonic anastomotic dehiscence with this device.

We describe the case of a 70-year-old man who underwent left colectomy for colon cancer. On the seventh postoperative day, fecal material appeared from his abdominal drain, but he had no signs of fever or peritonitis. A computed tomography (CT) scan of his abdomen confirmed the clinical suspicion of anastomotic dehiscence. We then performed an endoscopic evaluation, which confirmed the presence of a large anastomotic dehiscence ( $\triangleright$ Fig. 1 ).

We decided to treat the lesion with the Apollo Overstitch device. The procedure was carried out using $\mathrm{CO}_{2}$ insufflation, with the patient under conscious sedation. Initial tissue preparation prior to closure was done by creating a surgical surface using argon plasma coagulation at the immediate perimeter of the leak; subsequently, running sutures were placed with a distal to proximal technique, attempting to create a full-thickness suture ( Video 1). The procedure was successful with no complications occurring over the following days. However, because radiological follow-up performed a week later showed the persistence of a minimal leak at the site of the dehiscence, we decided to repeat the procedure with the Apollo device.

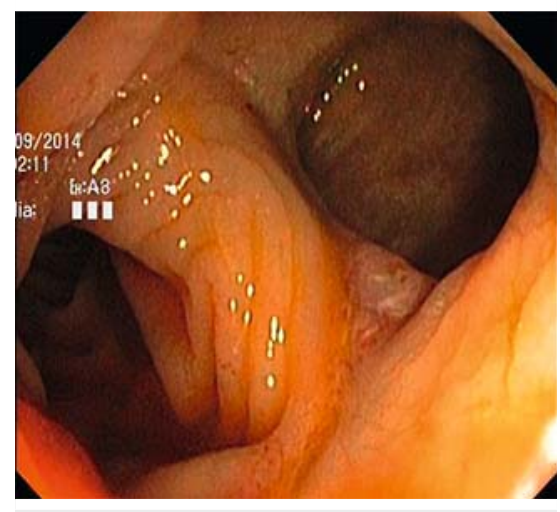

- Fig. 1 Endoscopic view showing the anastomotic dehiscence.

At 1 month after the second procedure, no complications or symptoms were reported; moreover, no further fecal material and no contrast leakage on radiological follow-up had been observed. Repeat endoscopic evaluation at 6 months showed complete closure of the dehiscence (> Fig. 2 ).

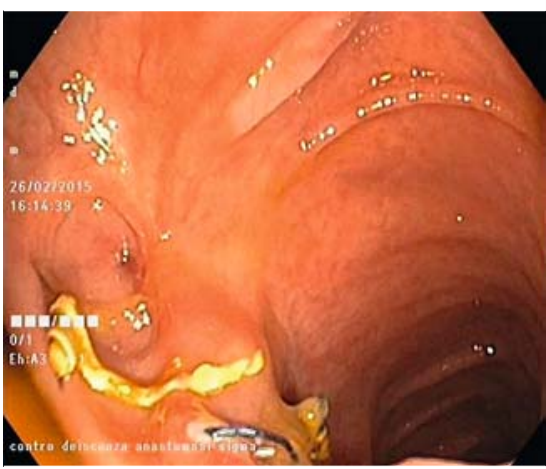

- Fig. 2 Repeat endoscopy at 6 months confirmed closure of the anastomotic dehiscence.

This clinical report demonstrates the effectiveness of an endoscopic suturing device for closure of postoperative colorectal leakage.

Endoscopy_UCTN_Code_CPL_1AJ_2AG

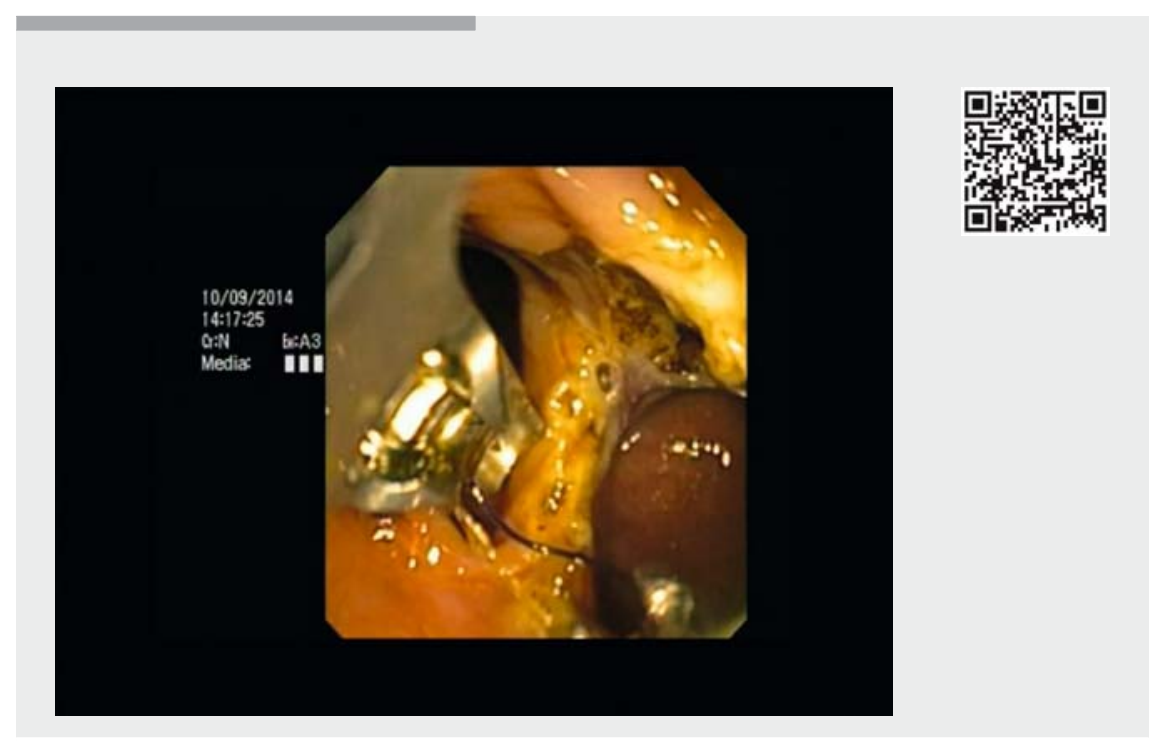

$\checkmark$ Video 1 Successful closure of an anastomotic dehiscence after colon - rectal cancer resection using the Apollo Overstitch suturing system. 


\section{Competing interests}

None

The Authors

Valerio Belfiori ${ }^{1}$, Fillipo Antonini ${ }^{1}$, Samuele Deminicis ${ }^{1}$, Barbara Marraccini ${ }^{1}$, Simona Piergallini ${ }^{1}$, Walter Siquini ${ }^{2}$, Giampiero Macarri ${ }^{1}$

1 Gastroenterology and Digestive Endoscopy Unit, “Murri” Hospital, Polytechnic University of Marche, Fermo, Italy

2 Surgical Department, "Madonna del Soccorso" Hospital, San Benedetto del Tronto, Marche, Italy

\section{Corresponding author}

\section{Valerio Belfiori, MD}

Gastroenterology and Digestive Endoscopy Unit, "Murri" Hospital, Polytechnic University of Marche, Via Murri, Fermo, Marche, Italy Fax: +39-734-6252252

vbelfiori@yahoo.it

\section{References}

[1] Watson R, Thompson C. Application of a novel suturing device in the Gl tract. Gastrointest Endosc 2011; 73: AB105

[2] Pauli EM, Delaney CP, Champagne B et al. Safety and effectiveness of an endoscopic suturing device in a human colonic treatand-resect model. Surg Innov 2013; 20 : 594-599

[3] Stavropoulos SN, Modayil R, Friedel D. Current applications of endoscopic suturing. World J Gastrointest Endosc 2015; 7: 777 789

[4] Kantsevoy SV, Bitner M, Hajiyeva G et al. Endoscopic management of colonic perforations: clips versus suturing closure (with videos). Gastrointest Endosc 2016; 84 : 487-493

[5] Sharaiha RZ, Kumta NA, DeFilippis EM et al. A large multicenter experience with endoscopic suturing for management of gastrointestinal defects and stent anchorage in 122 patients: a retrospective review. J Clin Gastroenterol 2016; 50: 388-392

\section{Bibliography}

DOI https://doi.org/10.1055/s-0043-108542

Published online: 14.6.2017

Endoscopy 2017; 49: 823-824

(c) Georg Thieme Verlag KG

Stuttgart · New York

ISSN 0013-726X

\section{ENDOSCOPY E-VIDEOS}

https://eref.thieme.de/e-videos

回回 Endoscopy E-Videos is a free Fection, reporting 口.: on interesting cases and new techniques in gastroenterological endoscopy. All papers include a high quality video and all contributions are freely accessible online.

This section has its own submission website at

https://mc.manuscriptcentral.com/e-videos 